\title{
The association between the use of antimicrobial growth promoters and development of resistance in pathogenic bacteria towards growth promoting and therapeutic antimicrobials
}

\section{H.C. Wegener, F.M. Aarestrup, L.B. Jensen, A.M. Hammerum and F. Bager}

Danish Veterinary Laboratory

Bülowsvej 27, DK-1790 Copenhagen V. Denmark

\begin{abstract}
The use of antimicrobial growth promoters has caused the development of resistance in a number of important pathogenic bacterial species. Furthermore, most cases in which antimicrobials belonging to one single class of antibiotics have been used as therapeutic drugs for both humans and animals have resulted in the development of cross resistance to these drugs. Some of the bacteria developing resistance are pathogenic to animals or man, and the development of resistance to growth promoters and related therapeutic drugs has limited the therapeutic options for these bacteria. In the case of E. faecitum, resistance has developed towards very important "last resort" antimicrobials. Although the full public health consequences of the development of resistance through the use of antimicrobial growth promoters have not yet been determined, there is nevertheless a need to take precautionary actions in order to prevent further development of resistance towards a number of antimicrobials used as growth promoters.
\end{abstract}

KEY WORDS: growth promoters, pathogenic bacteria, resistance

\section{INTRODUCTION}

A number of bacteria have been studied at the Danish Veterinary Laboratory to investigate if an association between the use of certain antibacterial growth promoters and development of resistance to therapeutically important antibiotics could be demonstrated. Resistance of Enterococcus faecium to the growth promoters avoparcin, virginiamycin and avilamycin in animals has been extensively studied. Furthermore, the transmission of resistant E. faecium and resistance genes from 
animals to man has also been investigated. For tylosin a range of different bacterial species have been studied, such as the animal pathogens Streptococcus suis, Staphylococcus hyicus and Mycoplasma hyosynoviae, and the zoonotic pathogen Campylobacter jejuni.

\section{AVOPARCIN/VANCOMYCIN}

Antimicrobials belonging to the class of glycopeptides have been used to treat infections with multiple antimicrobial-resistant, gram positive bacteria in hospitalised human patients (vancomycin) and as a feed additive to increase the growth rate of animals (avoparcin). It has been estimated that approx. $24 \mathrm{~kg}$ of vancomycin was used for human therapy in Denmark in 1994. In the same period $24.000 \mathrm{~kg}$ of avoparcin (active compound) was used as a feed additive for growth promotion in pig- and broiler production.

The number of outbreaks and sporadic cases of nosocomial infections with vancomycin resistant Enterococcus faecium (VRE) have been steadily increasing since the first cases were reported in 1988 (Anon, 1993). Infections with VRE cause high mortality as the organism is commonly resistant to all currently used antimicrobials. Infections primarily occur in intensive care patients, and certain patients are at increased risk for VRE infection or colonisation. Multiple factors predispose to the development of infection with VRE, but colonisation of the gastro-intestinal tract precedes most infections (Edmond et al., 1995).

In the light of the increasing incidence of human VRE infections in hospitals, efforts have been made in several countries to prevent the spread of vancomycin resistant bacteria. These efforts have led to the development of specific recommendations for hospitals (Anon, 1995). One of the important control measures recognised in Europe is the prevention of the introduction of VRE into hospitals from community sources (van der Auwera et al., 1996).

Recent studies from several countries in Europe have shown a strong association between the use of avoparcin as a growth promoter for animals and the occurrence of VRE in animals and food (Bates et al., 1994; Aarestrup, 1995; Klare et al., 1995; Bager et al., 1997). The detection of VRE in livestock and fresh meat suggests that humans are exposed to VRE either by direct contact with animals or from consumption of meat. This hypothesis has later found support from several independent lines of evidence:

- the finding in European countries, where avoparcin has been used as a growth promoter, of high carrier rates of VRE in healthy humans outside the hospital setting, compared to USA, where VRE could not be detected in the community - including samples from healthy humans (Gordts et al., 1995; Coque et al., 1996; van der Auwera et al., 1996), 
- when human meat-eaters and vegetarians in Europe were compared, VRE was only detected in meat-eaters, whereas VRE could not be detected in vegetarians (Schouten et al., 1997),

- identical strains of VRE have been isolated from humans and animals, both in studies of randomly isolated bacteria and in cases where a close contact between humans and animals/food existed (Anon, 1995; van den Bogaard et al., 1997).

The genetic element conferring high-level resistance to glycopeptides in most strains of VRE has been designated vanA. VanA is located on a transposon (a mobile genetic element designated "Tn1546"). Although some variations in terms of base sequence variations and insertion elements have been found in $\operatorname{Tn} 1546$, identical types of vanA have been detected in VRE of animal and human origin. The most likely explanation for this, is that the vanA gene, conferring glycopeptide resistance in VRE, has a common origin in animals and humans (Jensen et al., 1996; van den Bogaard et al., 1997; Woodford et al., 1997).

We have investigated the gene cluster encoding for vancomycin resistance in animal and human VRE. The gene cluster consists of several different genes. The coding regions, as well as the regions between them, were compared by sequencing of selected areas, PCR amplification of other areas and hybridization with specific probes (Jensen et al., 1998).

A total of 13 different types was observed, however, only one single nucleotide difference in the coding sequences was observed. This point mutation occurred in the $\operatorname{van} X$ gene at position 8234 where a $\mathrm{G}$ had been substituted by a T. This mutation was evenly distributed among human VRE isolates. In contrast, in isolates of poultry from several different countries only the $\mathrm{G}$ variant occurred, while in isolates of swine from several different countries only the $\mathrm{T}$ variant occurred. Although we have no explanation for this uneven distribution between different animals, the finding of both types in humans supports the view that animals are the primary source of vancomycin resistance genes in humans. In contrast, humans do not serve as a reservoir for animals, for in that case both types would have been expected to occur in both animal species.

McDonald et al. (1997) recently published a comprehensive review on the prevalence, sources and public health implications of VRE outside the health-care setting. In this paper the authors concluded that avoparcin is an important factor associated with the occurrence of VRE in the community in Europe, and furthermore, that evidence suggests that food-borne VRE may cause human colonisation in Europe.

Therefore, control of VRE in animals is an integral part of the control of human VRE infections in Europe. Reduction of the prevalence of VRE in animals will most likely- reduce the exposure to humans via food and ultimately reduce the 
number of human carriers of VRE in the community. Thus, it can be expected that the population potentially carrying VRE into hospitals will be reduced. Furthermore, the level of VRE contaminated food-stuffs entering the hospital kitchens may be reduced.

Based on the available evidence the EEC Commission decided in 1996 to ban the use of avoparcin as a growth promoter from 1 April 1997. The Commission recognised that there was a lack of information on this issue but chose to take a precautionary approach. In 1997, the FDA prohibited the extralabel use of glycopeptides in food-producing animals in the United States. This ruling was based on the recognition by the FDA that such use would lead to an increased risk of the transfer of resistant organisms to humans and would thus compromise human therapy (Anon, 1997).

It is important to recognise that these precautionary steps were taken, not only in the light of the present situation with VRE problems in Europe, but also to prevent a future increase in the problems with VRE in the health sector as well as to prevent glycopeptide resistance in other bacteria such as streptococci and staphylococci.

The ban on avoparcin was made in the expectation that removal of the selective pressure on VRE in animals would initially stabilise and ultimately reduce the exposure of humans to VRE from animals via food. The use of avoparcin as a growth promoter was banned in Sweden in 1986, in Denmark on $20^{\text {th }}$ May 1995, and in Germany on $19^{\text {th }}$ January 1996, and in the rest of the EEC on 1st April 1997. Thus the discontinuation of the use of avoparcin as a growth promoter in EEC, with the exception of Sweden, is a very recent event. Therefore, it is not yet possible to determine what effect the prohibition will have on the prevalence of VRE in European livestock and food in the long term.

The results of the Danish antimicrobial resistance monitoring programme (DANMAP) have shown that VRE could be detected among $E$. faecium isolated from faecal samples collected from Danish pigs, broilers and cattle during the period from October 1995 to September 1996 at rates of 29,59 and 0\%, respectively (Anon, 1997a). The data for 1997 show a marked reduction in VRE from broilers, whereas no significant change has occurred in pigs so far (Anon, 1998).

In Germany a decrease has been detected in the VRE carrier rate among healthy humans over the period in question (Klare, personal communication). In 1994 the carrier level was found to be $13 \%$. This level had decreased to approx. $4 \%$ in 1997. A plausible explanation for this change is reduced exposure to VRE from food as a result of the withdrawal of avoparcin from animal feed.

The Commission decided that a monitoring programme should be initiated with the aim of monitoring resistance to antimicrobial growth promoters in enterococci in a number of member states in the union. If this programme is continued for a sufficient number of years, it may provide us with information on the changes in 
VRE occurrence after the prohibition. Unfortunately, a monitoring programme was not in place in any EEC member state before the ban. Thus, there are no data available to compare the pre-ban to the post-ban period.

Data from Sweden show that avoparcin has not been used for animals since $1988(26 \mathrm{~kg})$, and that between 1984 and 1986 the consumption of avoparcin had already been markedly reduced (from $9.200 \mathrm{~kg}$ to $650 \mathrm{~kg}$ ) (Björneroth, 1996). Investigations have shown that VRE could not be detected in samples of Swedish animals and food-stuffs in 1996 (Quednau et al., 1996). These findings might suggest that VRE has disappeared over a 10 year time period. However, it should not be overlooked that no investigations have been carried out to show whether VRE was actually present in Swedish animal production prior to the prohibition and if so at what level.

\section{VIRGINIAMYCIN/SYNERCID}

The first drug for humans with a good clinical effect against VRE infections is now ready to be marketed, nearly 10 years after the first VRE was discovered. This drug called Syncrcid belongs to the class of streptogramins.

Another streptogramin product, called virginiamycin, has for a long time been used as a growth promoter in Europe and in the USA primarily for poultry production. Studies in the USA, the Netherlands and Denmark have shown that Synercid resistant enterococci can frequently be found in poultry everywhere (Anon., 1997a; van den Boogard et al., 1997a; Aarestrup ct al., 1998; Anon., 1998; Welton et al., 1998).

Moreover, the same resistance gene ( $s a t A$ ), conferring resistance to virginiamycin and Synercid, has been found in animals and humans (Hammerum et al., submitted). Thus, it seems that the association between the use of avoparcin and the occurrence of VRE also exists for virginiamycin and Synercid resistant E. faecium.

\section{AVILAMYCIN/ZIRACIN}

The drug Ziracin, which was expected to be next in line after Synercid, belongs to the class of everninomicins. It is practically identical to another growth promoter, called avilamycin, which has primarily been used for poultry in Denmark. We have observed a high occurrence of avilamycin resistant $E$. faecium in broilers in Denmark (69\% of isolates), compared to only very low levels of resistance $(2 \%)$ in E. faecium isolates from pigs (Aarestrup, 1998).

We have found that resistance to avilamycin confers cross-resistance to Ziracin and that a transferable genetic clement is probably involved (Aarestrup, submit- 
ted). Thus, again it seems that the use of an antibacterial drug as a growth promoter has created an animal reservoir of resistant enterococci, threatening to shorten the life-span of the "new" drug when it is put to use in humans.

\section{TYLOSIN/ERYTHROMYCIN}

We have recently completed a number of studies to investigate the effect of the growth promoter tylosin on the development, in bacteria from food animals, of resistance towards macrolides, including those macrolides that are used for therapy in animals and humans (Anon, 1998a). An association between the use of tylosin and the occurrence of elevated levels of resistance was shown for a number of animal pathogens (Streptococcus suis, Mycoplasma hyosynoviae, Staphylococcus hyicus and Serpulina hyodysenteriae) (Aarestrup et al. 1998a; Aarestrup and Friis, 1998; Anon, 1998a). Furthermore, a similar association was indicated for the zoonotic pathogen Campylobacter coli (Aarestrup et al., 1997).

\section{CONCLUSIONS}

The use of antimicrobial growth promoters causes the development of resistance in a number of bacterial species in the exposed animals. Cross-resistance to the therapeutic drug exists in most cases where the growth promoter belongs to the same class of antibiotics as the therapeutic drug. Some of the bacteria developing resistance are pathogenic to animals or man, and the development of resistance to growth promoters and related therapeutic drugs limits the therapeutic options for these bacteria. In the case of $E$. faecium, resistance has developed towards very important "last resort" antimicrobials through the use of growth promoters. Although the full public health consequences of this development have not yet been determined, there is an immediate need to take precautionary action to prevent further resistance being developed towards these important drugs.

The core of the problem seems to be that the pharmaceutical industry is no longer able to develop new drugs to fight the increasing problems of multi-resistant gram positive infections. Instead, they modify and improve old drugs. These same classes of drugs have for decades been used for growth promotion of animals, because nobody thought they were ever going to be needed for humans. Now, when they are needed, it may be too late, - because resistance has already been developed by bacteria in food animals, and this resistance can be transmitted to humans through the food chain. 


\section{REFERENCES}

Aarestrup F.M., 1998. Occurrence of resistance in E. faecium from food animals towards everninomicins avilamycin used as a growth promoter and Ziracin, a new therapeutic antimicrobial for use in humans. Antimicrob. Agents Chemother. (in submission)

Aarestrup F.M., Bager F., Madsen M., Jensen N.E., Meyling A., Wegener H.C., 1998. Surveillance of antimicrobial resistance in bacteria isolated from food animals to growth promoters and related therapcutic agents in Denmark. APMIS (in press)

Aarestrup F.M., Friis N.F., 1998. Antimicrobial susceptibility testing of Mycoplasma hyosoniviae isolated from diagnostic samples in pigs during 1968 to 1971 and during 1995 and 1996. Vet. Microbiol. (in submission)

Aarestrup F.M., Jorsal S.E., Jensen N.E., 1998a. Serological characterization and antimocrobial susceptibility of Streptococ'us suis isolates from diagnostic samples in Denmark during 1995 and 1996. Vet. Microbiol. (in press)

Aarestrup, F.M., 1995. Occurrence of glycopeptide resistance among Enterococcus faecium isolates from conventional and ecological poultry farms. Microb. Drug Resist. 1, 255-257

Aarcstup F.M., Nielsen E.M., Madsen M., Engberg J., 1997. Antimicrobial susceptibility patterns of thermophilic Campylobacter spp. from humans, pigs, cattle, and broilers in Denmark. Antimicrob. Agents Chemother. 41, 2244-2250

Anon., 1993. Centers for Disease Control and Prevention. Nosocomial enterococci resistant to vancomycin - United States 1989-1993. Morbid. Mortal. Weekly Rep. 42, 597-600

Anon., 1995. Centers for Disease Control and Prevention. Recommendations for Preventing the Spread of Vancomycin Resistance. Recommendations of the Hospital Infection Control Practices Advisory Committee (HICPAC). Morbid. Mortal. Weekly Rep. 44, No. RR-12

Anon., 1995. The effect of avoparcin used as a feed additive on the occurrence of vanco-mycin resistant Enterococcus faecium in pig and poultry production. Report from the Danish Veterinary Laboratory. July, 1995

Anon., 1997. Department of Health and Humans Services, Public Health Service, U.S. Food and Drug Administration. Extralabel Animal Drug Use; Flouroquinolones and Glyco-peptides; Order of Prohibition. Federal Register 62, 118

Anon., 1997a. Consumption of antimicrobial agents and occurrence of antimicrobial resistance in bacteria from food animals, food and humans in Denmark. No. 1, February 1997. (ISSN 1397-078X). Publication from the Danish Integrated Antimicrobial Resistance Monitoring and Research Programme (DANMAP)

Anon., 1998. Consumption of antimicrobial agents and occurrence of antimicrobial resistance in bacteria from food animals, food and humans in Denmark. No. 2, May 1998. (ISSN 1397-078X). Publication from the Danish Integrated Antimicrobial Resistance Monitoring and Research Programme (DANMAP)

Anon., 1998. The effect of the growth promoter tylosin on bacterial resistance development and salmonella shedding. Report from The Danish Veterinary Laboratory (In Danish with English summary). 7 January 1998

Auwera P., van der Pensart N., Korten V., Murray B., 1996. Influence of oral glycopep-tides on the faecal flora of human volunteers: selection of highly glycopeptide resistant enterococci. J. Infec. Dis. 173, 1129-1136

Bager F., Madsen M., Christensen J., Aarestrup FM., 1997. Avoparcin used as a growth promoter is associated with the occurrence of vancomycin-resistant Enterococcus faecium on Danish poultry and pig farms. Prev.Vet. Med. 31, 95-112 
Bates J., Zoe Jordens J., Griffiths D.T., 1994. Farm animals as a putative reservoir for vancomycinresistant enterococcal infection in man. J. Antimicrob. Chemother. 34, 507-516

Björnerot L., 1996. Sweden banned the use of antibiotics as growth promoters in 1986 - what happened to the consumption? (in Swedish). K. Skogs-o. Lantbr.akad. Tidskr. 135, 15, 57-68

Bogaard A.E. van den, Mertens P., London N.H., Stobberingh E.E., 1997a. High prevalence of vancomycin- and pristinamycin resistant enterococci in healthy humans and pigs in The Netherlands: is the addition of antibiotics to animal feed to blame? Antimicrob. Agents Chemother. $40,454-456$

Bogaard A.E. van den, Jensen L.B., Stobberingh E.E., 1997. Vancomycin-resistant entero-cocci in turkeys and farmers. N. Engl. J. Med. (accepted for publication)

Coque T.M., Tomayko J.F., Ricke S.C., Okhuysen P.C., Murray B., 1996. Vancomycin-resistant enterococci from nosocomial, community and animal sources in the United States. Antimicrob. Agents Chemother. 40, 2605-2609

Edmond M.B., Ober J.F., Weinbaum, J.L., 1995. Vancomycin-resistant Enterococcus faecium bacteremia: risk factors for infection. Clin. Infect. Dis. 20, 1126-1133

Gordts B., Van Landuyt H., Leven M., Vandamme P., Goossens H., 1995. Vancomycin-resistant enterococci colonizing the intestinal tract of hospitalized patients. J. Clin. Microbiol. 33, 2842-2846

Hammerum A.M., Jensen L.B., Aarestrup F.M., 1998. Detection of the satA gene and transferabillity of virginiamycin resistance in Enterococcus faecium from food animals. (Submitted)

Jensen L.B., Ahrens P., Dons L., Jones R., Hammerum A.M., Aarestrup F.M., 1998. Molecular analysis of the Tn1546 from Enterococcus faecium isolated from animals and humans. (Submitted)

Jensen L.B., Ahrens P., Dons L., Jones R.N., Hammerum A., Aarestrup F.M., 1996. Genetic characterisation of the VanA gene clsuter in Enterococcus faecium isolates of human and animal origin from Europe and USA. Proceedings Fallen Leaf Lake Conference. Horisontal Gene Transfer: Implications and Consequences. South Lake Tahoe, California, USA

Klare I., Heier H., Claus H., Reissbrodt R., Witte W., 1995. vanA-mediated high-level glycopeptide resistance in Enterococcus faecium from animal husbandry. FEMS Microbiol. Lett. 125, 165-172

McDonald C.L., Kuehnert M.J., Tenover F.C., Jarvis W.R., 1997. Vancomycin-resistant cnterococci outside the health care setting: Prevalence, sources and public health implications. Emerging Infect. Dis. 3(3) (Available via the following internet address: ftp://ftp.cdc.gov/pub/EID/vol3no3/ ascii/macdonald.txt)

Quednau M., Ahrné S., Molin G., 1996. Antibiotic resistant enterococci in Swedish and Danish pork and poultry. Proceedings of Symposium on Food Associated Pathogens. Uppsala, Sweden, pp. 254

Schouten M.A., Voss A., Hoogkamp-Korstanje J.A.A., 1997. VRE and meat. The Lancet 349, 1258

Welton L.A., Thal L.A., Perri M.B., Donabedien S., McMahon J., Chow J.W., Zervos M.J., 1998. Antimicrobial resistance in enterococci isolated from turkey flocks fed virginiamycin. Antimicrob. Agents Chemother. 42, 705-708

Woodford N., Adebiyi A., Palepou M.-F., Cookson B., 1997. Comparison of vanA glycopeptide resistance elements in enterococci from humans and non-human sources. Proceedings Fourth International Meeting on Bacterial Epidemiological Markers (IMBEM IV). Elsinore, Denmark 